\title{
FTIR study of Achilles tendinopathy: protein secondary structure changes in tendon post injury
}

\author{
Tanmoy Bhattacharjee ${ }^{1}$, Mariana Nicodemo $^{2}$, Emilia Lo Schiavo Arisawa $^{2 *}$, Leandro Raniero ${ }^{1}$ \\ ${ }^{1}$ Laboratory of Nanosensors, Research and Development Institute, University of Paraíba Valley, São José dos Campos, SP, Brazil. \\ ${ }^{2}$ Biostimulation and Tissue Repair Laboratory, Research and Development Institute, University of Paraíba Valley, São José dos \\ Campos, SP, Brazil.
}

\begin{abstract}
Introduction: Tendinopathy, a disease involving tendon inflammation and damage, results in considerable productivity and economic losses for the patient and the society. Currently available diagnosis/ treatment monitoring modalities are less efficacious and highly subjective, underlying the need for better tools. Previously, we have shown that Fourier Transform Infrared (FTIR) spectroscopy has potential in tendinopathy diagnosis/ monitoring, when combined with multivariate statistical analysis. The current study explores the spectral range that gave the best results in statistical analysis, to discover protein secondary structures associated with tendon injury and recovery that can act as markers of disease. Methods: Animals $(n=60)$ underwent a surgery in which Achilles tendon were injured by dropping a $20 \mathrm{~g}$ weight. Rats were divided into three groups $(n=20)$ - control (C), Achilles tendon injury (I) and Achilles tendon injury treated with amniotic membrane fragment treated (T). FTIR spectra were obtained from each group 3, 7, 14, and 28 days post injury/ treatment. Results: Triple helix, $\beta$-turn, and disordered structure levels differ between control, injured and treated tendons over the time period studied. Parallel $\beta$-sheets increase steadily over time in treated tendons compared to control and injured. Conclusion: Combined analysis of Triple helix, $\beta$ - sheets, $\beta$-turn, and disordered structure levels may be useful for tendinopathy diagnosis and treatment monitoring. However, further studies in this area are required to confirm the findings.
\end{abstract}

Keywords Secondary structures, ATR-FTIR, Tendinopathy, Protein.

\section{Introduction}

Tendinopathy is a broad term including all non-rupture injury in tendon or paratendon (Scott et al., 2015). One of the most common tendinopathies is Achilles tendinopathy, accounting for half of all sports associated injuries (Pedowitz and Kirwan, 2013), and involves tendon inflammation and/or tendon collagen fibre separation. Although various diagnosis, treatment and monitoring modalities exist; they are subjective, less efficacious, and there is lack of consensus on the best methodology (Alfredson and Cook, 2007; Docking et al., 2015; Kvist, 1994; Lohrer et al., 2016). Considering the

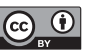

This is an Open Access article distributed under the terms of the Creative Commons Attribution License, which permits unrestricted use, distribution, and reproduction in any medium, provided the original work is properly cited.

How to cite this article: Bhattacharjee T, Nicodemo M, Arisawa ELS, Raniero L. FTIR study of Achilles tendinopathy: protein secondary structure changes in tendon post injury. Res Biomed Eng. 2018; 34(4):350-355. DOI: 10.1590/2446-4740.170089.

*Corresponding author: Biostimulation and Tissue Repair Laboratory, Research and Development Institute, University of Paraíba Valley, Av. Shishima Hifumi, 2911, CEP 12244-000, São José dos Campos, SP, Brazil. E-mail: mirela@univap.br

Received: 05 November 2018 / Accepted: 26 December 2018 economic and productivity losses associated with this ailment (Hopkins et al., 2016), discovery of a better diagnostic/ monitoring technique is imperative. In our previous study, we have shown that Attenuated Reflectance - Fourier Transform Infrared spectroscopy (ATR-FTIR) has potential in identifying injury and treatment progress (Bhattacharjee et al., 2018). However, the output is based complex mathematical models generated by Principal Component - Linear Discriminant Analysis (PC-LDA). This may not be enough to convince clinicians of the technique's translational capability. It will be much better to show underlying biochemical changes that forms the basis of the calculations and mathematical models.

While it is possible to identify biochemical changes by spectral peaks, difference spectrum calculations, and Principal Component Analysis (PCA) Loadings; these are generally limited to broad classes like lipids, proteins and nucleic acids, and usually do not provide more specifics. The reason is that vibrational spectroscopy provides classification/identification based on entire metabolome, rather than specific proteins/ biochemicals. In the case this tendon study, we found the classification to be best in the $1585-1720 \mathrm{~cm}^{-1}$ spectral range, which can provide information of protein secondary structure; giving a unique opportunity to explore for more specific changes 
that can be correlated to the classification and existing body of knowledge on injury and repair mechanisms. Thus, in this article, we report the secondary structural changes observed by ATR-FTIR spectra deconvolution in control, injured and treated tendons over the time period of 3-28 days post injury/ treatment.

\section{Methods}

This research was approved by Research Ethics Committee (350.427) and Animal Ethics Committee (A03/CEAU/2013). Sixty Wistar rats were divided into three groups: Control (C), Injury (I) and Treated (T) (20 rats/group). Each group was further sub-divided into four groups, according experimental time-3, 7, 14 and 28 days (5 rats/sub-group). Achilles tendon injury was performed in the rats of groups I and T with mini guillotine (Figure 1). The animals were submitted to a surgical procedure where the right leg of the animal was positioned at the base of the mini guillotine, keeping the ankle in dorsiflexion. A weight of $20 \mathrm{~g}$ was released from a fixed height $(20 \mathrm{~cm})$ over the flexed leg of the rat, causing transverse crushing of the fibers of the tissue relative to the long axis of the tendon. The weight was removed immediately after lesion (Neves et al., 2011).
It was applied a fragment of human amniotic membrane (hAM) to rats of $\mathrm{T}$ group as a treatment of injured tendon. The tendons of $\mathrm{C}$ rats were not injured, but a sham surgical exposure without application of hAM was performed to enable comparison on injury and treatment without interference of factors associated with surgery. After these procedures, rats were maintained under standard conditions. After 3, 7, 14 and 28 days of the surgical procedure, 5 rats belonging to the sub-groups were sacrificed. Injured regions of the tendons were obtained and analyzed for ATR-FTIR spectroscopy. Figure 1 depicts these procedures.

\section{ATR-FTIR and data analysis}

Spectra were acquired from the defrosted and dried samples using Diamond ATR Module coupled to a Perkin Elmer Spectrum 400 FTIR-spectrometer in $900-4000 \mathrm{~cm}^{-1}$ range, 64 scans per reading at a resolution of $4 \mathrm{~cm}^{-1}$. The spectra were interpolated in the $900-3700 \mathrm{~cm}^{-1}$ range, baseline of polynomial order 5 subtracted and vector normalized. The spectra were interpolated in the Amide I region $\left(1585-1720 \mathrm{~cm}^{-1}\right)$, deconvoluted for peaks identified by Find Peaks feature (threshold: $30 \%$ by height) based on second derivative, fitted
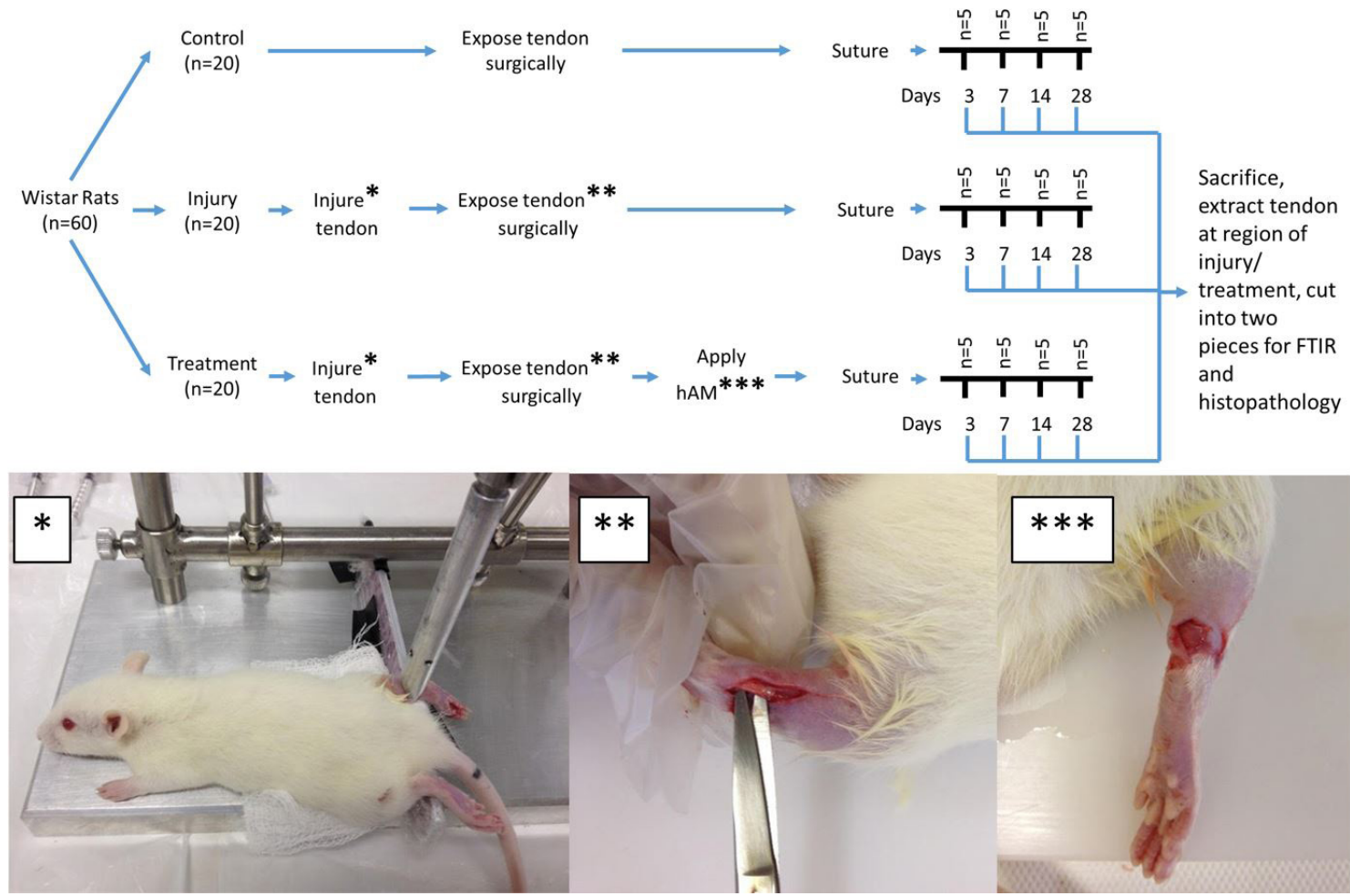

Figure 1. Methodology overview: Wistar rats were divided into three groups - control, injury, and treatment. In injury group, rat tendons were injured, while in treatment group, human Amniotic Membrane (hAM) was applied to injured treatment after injury. These procedures were not applied in control. Five rats from each group were sacrificed on days 3, 7, 14, and 20 post injury, and injured/treated region of the tendon excised. Part of this tissue was used for FTIR while the other half underwent histological evaluation. 
with Gaussian curve and area calculated using Origin Pro 8.5 after further. Secondary structure assignments were done based on previous literature (Barth, 2007; Chadefaux et al., 2009).

\section{Results}

Figure 2 shows the mean and standard deviation (SD) for Amide I region of all spectra. The SD is comparatively higher for C days 7-28, and day 7 C, I, and T. Despite this, we can assume mean spectra of each group to be representative of the group, but keep in mind the SDs during interpretation.

In order to better understand the variations in this region, the spectral range was deconvoluted based on peaks seen after second derivatization. Gaussian curves were fitted to each peak, and area under the curves calculated. The peaks mostly corresponded to protein secondary structures. A table showing the percent areas under the curves for each secondary structure is shown in Table 1. Percentage was calculated by dividing area under a particular peak by total area under all peaks for that particular time-point and condition and multiplying the result by 100 . For example, to calculate percent triple helix for control day 3 , area under triple helix was divided by sum of all areas under the curve in control day 3 and multiply the result by 100 .
It is not easy to visualize the changes in table form. Hence, the areas were plotted over days for each secondary structure assignment separately. The graphs are shown in Figure 3.

Triple helix shows major changes in I and $\mathrm{T}$ when compared to $\mathrm{C}$. The trend in $\mathrm{I}$ is opposite to $\mathrm{C}$, that is, triple helix in $\mathrm{C}$ increases on days 7 and 14 with respect to day 3 , and then decreases to level of day 3 on day 28, while triple helix in I decreases over days 7 and 14 before rising to the level of $\mathrm{C}$ on day 28. In case of $\mathrm{T}$, triple helix is very high compared to $\mathrm{C}$ and $\mathrm{I}$, but steadily decreases over days 7 and 14, and is lowest on day 28. $\alpha$-helix remains relatively similar in $\mathrm{C}$ and I over all the time points. It shows level similar to $\mathrm{C}$ and $\mathrm{I}$ in $\mathrm{T}$ at all days, except day 14 when it is high compared to $\mathrm{C}$ and $\mathrm{I}$. Parallel $\beta$ - sheets too show similar levels over the period of study for $\mathrm{C}$ and $\mathrm{I}$, but steadily increases in $\mathrm{T}$, with days 14 and 28 having higher levels than $\mathrm{C}$ and I. Little variation between $C$, I, and T is observed in anti-parallel $\beta$ - sheet levels. $\beta$ - turn levels remain constant over the time period of study for all three groups, although their levels are in the order I $>C>$ T. Also, on day 28, levels for I and T become same. Disordered structures fluctuate considerably in $\mathrm{C}$ over time. In case of $\mathrm{I}$, it decreases on day 7 , but steadily rises after that. Opposite trend is observed in $\mathrm{T}$ - disordered structure level is highest on day 7 but decreases till day 28 .
Day 3
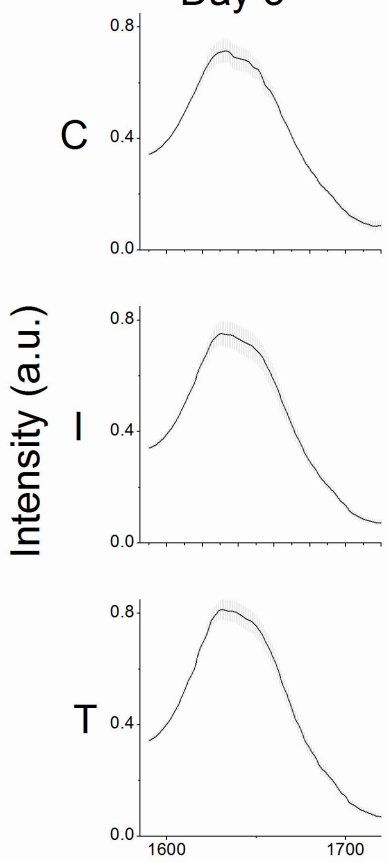

Day 7
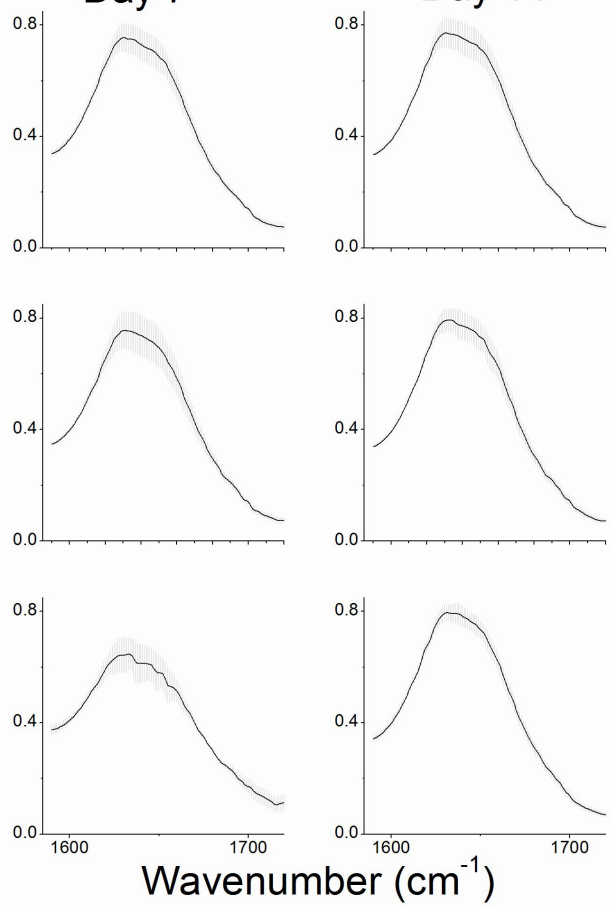

Day 14
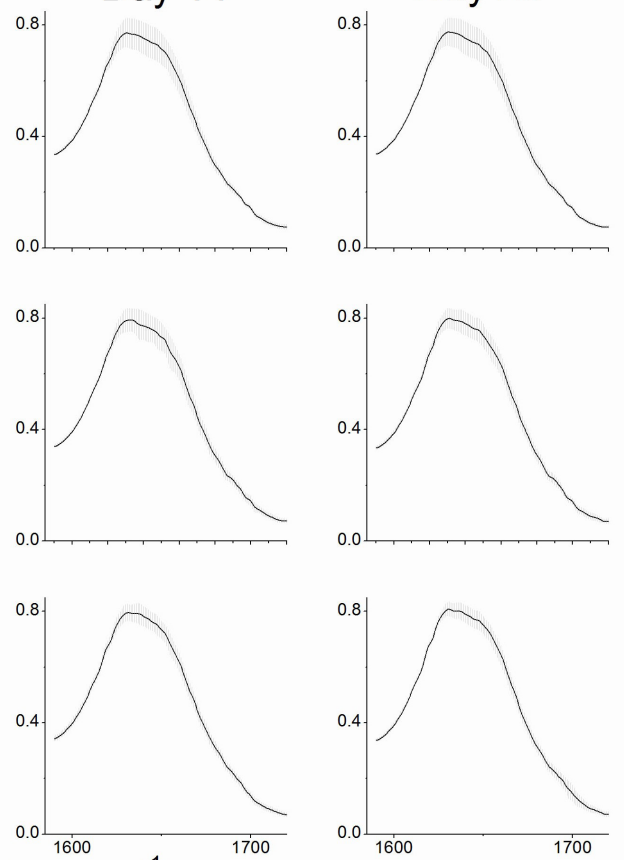

Figure 2. Mean spectra and standard deviation: The mean spectra and standard deviations in Amide I region for each group Control (C), Injury (I) and Treated $(\mathrm{T})$ at different time points 3-, 7-, 14- and 28-days post injury are shown. 
Table 1. Percent secondary structure content: The percentage of secondary structure distribution in different groups at different time points is listed. Secondary structure assignment with wavenumbers are mentioned below the table.

\begin{tabular}{|c|c|c|c|c|}
\hline $\mathrm{C}$ & Day 3 & Day 7 & Day 14 & Day 28 \\
\hline Triple helix & 12.5 & 18.4 & 19.5 & 12.6 \\
\hline$\alpha$-helix & 12.7 & 22.7 & 16.3 & 18.4 \\
\hline$\beta$-sheets (parallel) & 16.3 & 13.1 & 14.3 & 19.3 \\
\hline$\beta$-sheets (anti-parallel) & 17.8 & 14.3 & 15.5 & 15.2 \\
\hline$\beta$-turns & 19.3 & 18.8 & 18.6 & 19.7 \\
\hline Disordered & 17.8 & 8.7 & 15.8 & 7.5 \\
\hline I & Day 3 & Day 7 & Day 14 & Day 28 \\
\hline Triple helix & 18.6 & 6.9 & 9.1 & 16.5 \\
\hline$\alpha$-helix & 14.5 & 19.0 & 18.8 & 17.0 \\
\hline$\beta$-sheets (parallel) & 15.2 & 16.5 & 13.2 & 15.2 \\
\hline$\beta$-sheets (anti-parallel) & 15.0 & 14.9 & 16.5 & 14.5 \\
\hline$\beta$-turns & 21.6 & 23.1 & 22.9 & 16.9 \\
\hline Disordered & 15.0 & 3.0 & 8.8 & 20.0 \\
\hline $\mathbf{T}$ & Day 3 & Day 7 & Day 14 & Day 28 \\
\hline Triple helix & 28.0 & 12.5 & 9.6 & 4.9 \\
\hline$\alpha$-helix & 18.3 & 23.6 & 25.1 & 19.6 \\
\hline$\beta$-sheets (parallel) & 11.8 & 16.2 & 19.2 & 27.0 \\
\hline$\beta$-sheets (anti-parallel) & 16.6 & 14.7 & 13.5 & 16.3 \\
\hline$\beta$-turns & 17.8 & 14.5 & 16.1 & 16.6 \\
\hline Disordered & 1.5 & 10.5 & 7.0 & 2.6 \\
\hline
\end{tabular}

Triple helix (1633-1638); $\alpha$-helix (1651-1662); parallel $\beta$-sheets (1621-1630); anti-parallel $\beta$-sheets (1673-1680); $\beta$-turns (1611-1619 and 1667-1668); Disordered (1641-1648); C = Control; I = Injury; T = Treatment.
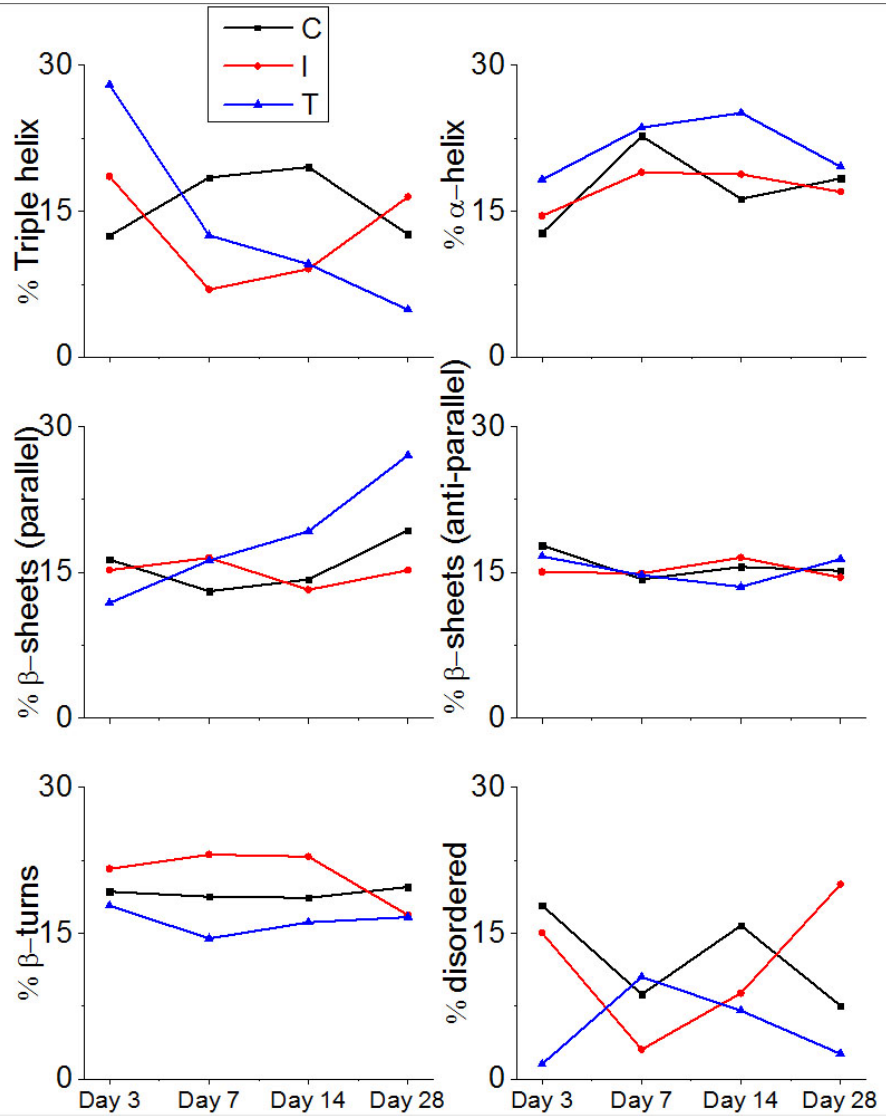

Figure 3. Trends of secondary structure change over time - the percent content of each secondary structure for each group over time is plotted. 


\section{Discussion}

It is evident from the results that triple helix and disordered structures levels differ between control, injured and treated tendons over the time period studied. Levels of the same can thus be used to distinguish healthy tendons from diseased. Monitoring of treatment efficacy can make use of the fact that parallel $\beta$ - sheets increase steadily over time in treated tendons compared to control and injured. The level of $\beta$-turns can provide further evidence for the same, as its levels are opposite between injured and treated with respect to control. We propose that a combined analysis of triple helix, disordered structures, parallel $\beta$ - sheets and $\beta$ - turns levels and their change over time can provide reliable diagnosis and treatment monitoring for tendons.

In our previous studies, we have shown that hAM treatment leads to better tendon repair, and also that these conditions - healthy, injury and repair can be classified using PC-LDA. The different time points used within the study can also be classified in each group, providing a convenient means to identify whether a given tendon is healthy or injured, as well as the status of repair, if any. However, as mentioned earlier, clinicians prefer to see changes in biochemicals associated with the disease, as opposed to results and classifications obtained from complex mathematical modelling. In this article, we have discerned the protein structural changes that underlie the classification and have identified specific changes that provide a means to distinguish the conditions.

It is interesting and important to correlate the changes identified with existing knowledge of tendon injury and repair. It has been established that injury can result from sudden trauma or chronic stress. In both cases, there is definite evidence to tear in tendon, disorganization of collagen fibers, loss in cross-linking among these fibers, and decrease in extracellular matrix. The injury is followed by repair period, which can be divided into three phases - inflammation, proliferation, and maturation (Holey, 2000; Weintraub, 2003). Inflammation involves recruitment of inflammatory factors and can last up to 3 - 7 days. Proliferation phase consists of collagen production, specifically type III collagen, and lasts up to 21 days or more. The phase is followed by maturation, which can last up to a year or more, and involves remodeling of collagen, and replacement of type III by type I collagen. Some of these characteristics, such as collagen fiber disorganization and tear, is seen as loss of triple helix in injured tendons up to day 3 , and subsequent increase in the same in proliferation phase denotes collagen synthesis. The above however does not explain why disordered structures decrease up to day 3 in injured tendons, and then steadily rise.

It is expected that the secondary structure levels should not change in control tendons. However, the literature strongly suggests that it is not true, and then minor changes continuously occur in healthy tissues under day to day stress. Further, we have already mentioned that the $\mathrm{SD}$ for $\mathrm{C}$ is high, which may also contribute to the fluctuations observed.

There is paucity of literature on biochemical changes in accelerated healing/ on treatment, which makes the finding of increasing parallel $\beta$ - sheets in treated tendon interesting. One explanation is that this represents proteoglycan synthesis, which has been reported to play an important part in healing (Silver and Rossdale, 1983; Xu and Murrell, 2008). Decrease in triple helix in treated tendons however cannot be explained, as it is expected that collagen synthesis will be accelerated in treated tendon.

While the study reveals some interesting points regarding secondary structure change, it suffers from the disadvantage of sample processing. All tissues underwent drying and freeze-thaw cycles, which affects the secondary structure. In general, freeze-drying results in a decrease of alpha-helix and random structure and an increase in beta-sheet structure (Roy and Gupta, 2004). Protein unfolding and denaturation is also a feature in many proteins (Bhatnagar et al., 2007). However, as all samples were freeze-dried in the same manner, the relative changes observed are still valid. Further studies in this direction may help resolve the problem.

In the current study, we attempted to identify biochemical/ secondary structural changes, that can link underlying tendon injury and repair mechanisms to classification obtained using mathematical modelling. Previously, we had found that PC-LDA can classify control, injured and treated tendons, as well as their states at different time points 4 weeks post injury/treatment. In this study, we found variation in the amount of triple helix, disordered structures, parallel $\beta$ - sheets and $\beta$ - turns in proteins between control/injury/treatment over different time points. We expect that these markers may aid identification of injured tendon, and monitor progress of treatment. It should however be noted that the samples underwent drying and freeze-thaw cycles which affects protein secondary structure. Moreover, the study is based on spectra from 5 animals per time point (resulting in 20 animals per group), and thus suffers from low sample size. Also, many of the observations could not be explained based on existing literature, and mechanisms known. Thus, further investigations in this direction is imperative.

\section{References}

Alfredson H, Cook J. A treatment algorithm for managing Achilles tendinopathy: new treatment options. Br J Sports Med. 2007; 41(4):211-6. http://dx.doi.org/10.1136/bjsm.2007.035543. PMid:17311806.

Barth A. Infrared spectroscopy of proteins. Biochim Biophys Acta. 2007; 1767(9):1073-101. http://dx.doi.org/10.1016/j. bbabio.2007.06.004. PMid:17692815. 
Bhatnagar BS, Bogner RH, Pikal MJ. Protein stability during freezing: separation of stresses and mechanisms of protein stabilization. Pharm Dev Technol. 2007; 12(5):505-23. http:// dx.doi.org/10.1080/10837450701481157. PMid:17963151.

Bhattacharjee TT, Nicodemo MC, Sant'Anna LB, Lo Schiavo Arisawa EA, Raniero L. Tendinopathy diagnosis and treatment monitoring using attenuated total reflectance-Fourier transform infrared spectroscopy. J Biophotonics. 2018; 11(4):e201700256. http://dx.doi.org/10.1002/jbio.201700256. PMid:29160619.

Chadefaux C, Le Hô A-S, Bellot-Gurlet L, Reiche I. Curvefitting Micro-ATR-FTIR studies of the amide I and II bands of type I collagen in archaeological bone materials. e-Preservation Science. 2009; 6:129-37.

Docking SI, Ooi CC, Connell D. Tendinopathy: is imaging telling us the entire story? J Orthop Sports Phys Ther. 2015; 45(11):842-52. http://dx.doi.org/10.2519/jospt.2015.5880. PMid:26390270.

Holey L. Tendon and ligament healing. Physiother. 2000; 86(6):326. http://dx.doi.org/10.1016/S0031-9406(05)61010-3.

Hopkins C, Fu S-C, Chua E, Hu X, Rolf C, Mattila VM, Qin L, Yung PS, Chan KM. Critical review on the socio-economic impact of tendinopathy. Asia Pac J Sports Med Arthrosc Rehabil Technol. 2016; 4:9-20. PMid:29264258.

Kvist M. Achilles tendon injuries in athletes. Sports Med. 1994; 18(3):173-201. http://dx.doi.org/10.2165/00007256199418030-00004. PMid:7809555.
Lohrer H, David S, Nauck T. Surgical treatment for Achilles tendinopathy: a systematic review. BMC Musculoskelet Disord. 2016; 17(1):207. http://dx.doi.org/10.1186/s12891-016-10614. PMid:27165287.

Neves MAI, Pinfildi CE, Wood VT, Gobbato RC, Silva FM, Parizotto NA, Hochman B, Ferreira LM. Different power settings of LLLT on the repair of the calcaneal tendon. Photomed Laser Surg. 2011; 29(10):663-8. http://dx.doi.org/10.1089/ pho.2010.2919. PMid:21668375.

Pedowitz D, Kirwan G. Achilles tendon ruptures. Curr Rev Musculoskelet Med. 2013; 6(4):285-93. http://dx.doi.org/10.1007/ s12178-013-9185-8. PMid:24151122.

Roy I, Gupta MN. Freeze-drying of proteins: some emerging concerns. Biotechnol Appl Biochem. 2004; 39(2):165-77. http://dx.doi.org/10.1042/BA20030133. PMid:15032737.

Scott A, Backman LJ, Speed C. Tendinopathy: update on pathophysiology. J Orthop Sports Phys Ther. 2015; 45(11):83341. http://dx.doi.org/10.2519/jospt.2015.5884. PMid:26390273

Silver I, Rossdale P. Biochemistry and pathology of tendon injury and healing. Equine Vet J Suppl. 1983; 1:5-22.

Weintraub W. Tendon and ligament healing: a new approach to sports and overuse injury. New Mexico: Paradigm Publications; 2003.

Xu Y, Murrell GA. The basic science of tendinopathy. Clin Orthop Relat Res. 2008; 466(7):1528-38. http://dx.doi.org/10.1007/ s11999-008-0286-4. PMid:18478310. 